\title{
Analysis of effectiveness of fire safety in machinery spaces
}

\author{
James McNay, Romanas Puisa, and Dracos Vassalos
}

\begin{abstract}
The primary cause of machinery space fires is cited as the release of flammable oil mist contacting unprotected hot surfaces. With this being common knowledge why do we continue to see this type of incident reoccurring on ships carrying thousands of passengers to precarious destinations? We review regulatory and Class requirements with respect to fire safety, Formal Safety Assessment (FSA) as a rule-making instrument of the IMO, accident investigation recommendations involving fire, fire safety technology, and research literature. For each constituent of fire safety control, the paper aims to determine the preferred strategies for accident prevention and their relative cost effectiveness. Subsequently, the cost effectiveness of the current safety approach is established. This review found that fire prevention could be made more cost effective if its scope was broadened beyond the detection of proximate events occurring immediately before ignition. The findings suggest that more cost-effective safety measures can be developed by addressing systemic causes of fire. Removal of the systemic causal factors of fire from the equation, means we can address fire safety prior to the moments before ignition when the point of no return can unwittingly be passed. The paper suggests directions of how this can be achieved.
\end{abstract}

\section{Introduction}

\subsection{Background}

In the top causes of loss where this results in a maritime claim, fire ranks second on the list by the number of claims at $16 \%$, and also second in value of claim (1). Fire in machinery spaces, such as engine and boiler rooms, have been singled out by cruise ship and roll-on/ roll-off (RoPax) operators as a primary focus, singularly or collectively striving to contain this risk (2, 3). Between August 2011 and January 2018, amongst 112 'serious' and 'very serious' fire incidents (as defined by EMSA), 57 were in the machinery spaces (4). More than a decade ago, a study by Det Norske Veritas (DNV) reported that about half of fires that occurred in machinery spaces resulted from the contact between combustible oil mist and high temperature surfaces (5). Little has changed since then, for this very scenario remains rife today (6).

The approach to fire safety is meant to reflect knowledge of how fires happen and develop, and, therefore, implement methods whereby fires shall be prevented or at least controlled. Prevention and control (or mitigation) are complementary and can be seen as two sequential, redundant, and relatively independent barriers against fire development. These generic barriers can be implemented in many ways, but there are certain, preferred methods of putting them into practice. These ways are informed by experience, fire safety tradition, technological and programmatic constraints, as well as the input from accident investigation. The latter plays a special role, for it arguably creates new knowledge by explaining what happened and how this can be avoided next time (Figure 1). Although maritime accident investigation 
recommendations are aimed at shipping companies, they often also have a ripple effect across the whole industry, affecting safety rules and their implementation, offered technology, design and operational decisions, and the course of research. A notorious example is the fire on passenger ferry Scandinavian Star in 1990 which triggered a comprehensive revision of the International Code for Fire Safety Systems in 1992 and affected the approach to fire protection and evacuation (7).

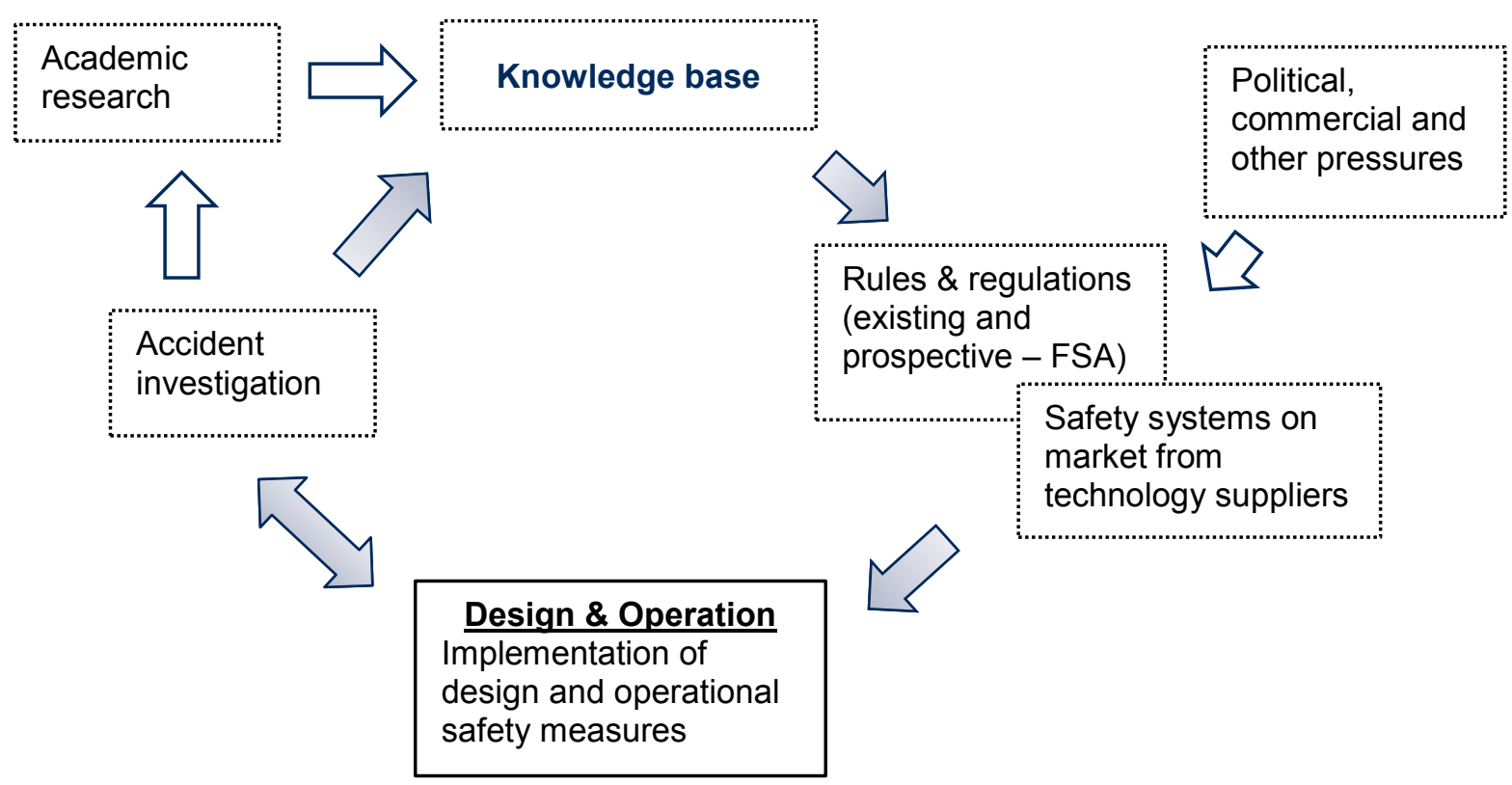

Figure 1: Evolutionary process to safety

Accident investigations begin with prior assumptions at hand, i.e. an accident model - the understanding of how fires, and accidents in general, occur. The prior assumptions prompt what to look for and what will therefore be found (8). Subsequently what is found, is recommended to be fixed. The problem is that these assumptions can be flawed on some fundamental aspects, leading to ineffective safety rules, regulations, good practices, and, in part, safety systems. This results in inadequate hazard control and therefore incidents. On the other hand, the ineffectiveness may also be unwittingly introduced by political, commercial and other pressures (Figure 1). Statutory safety rules in particular are a result of a consensus between rule givers (i.e. regulators) and rules takers (i.e. operators, designers) (9). Thus, in the strict sense, safety rules cannot be said to set either a minimal or average safety level, but merely an agreed safety level.

Flaws in prior assumptions about how incidents occur, and hence how they can be prevented, has attracted much attention over the last few decades. Pre-ignition events take time to develop. Conditions (e.g., wrong design assumptions, presence of design limitations) would lead to events or other conditions (e.g., ill-informed management, training, and O\&M procedures), which in turn lead to other events and conditions and so on. The metaphors like "incubation period" and "drifting into failure" are used to explain the dormant, latent conditions in a system that, with time, insidiously degrade the system to the point when an incident becomes imminent $(10,11)$. This degradation or drift is systematic (not random) and fuelled by natural phenomena of adaptation to new circumstances (endogenous and exogenous) and optimisation of resources (12); it is also explained as the inexorable manifestation of entropy. 
A helpful property of this dynamic is its relative slowness and determinism, which means that the drift is detectable and preventable $(13,14)$. On the other hand, this natural system dynamic undermines the utility of accident investigation results that inevitably reflect the past circumstances which may not remain relevant $(15,16)$.

The important realisation is that the underlying system behaviour cannot be changed by merely looking for or reacting to its events, or by analysing components of the system in isolation (17). Therefore, increasing the layers of protection does not necessarily lead to safety in socio-technical systems because additional safety barriers and protection can be defeated by psychological reactions (18). The reason being that a socio-technical system is more than the sum of its components (12). Thus, the cause of an incident and accident is the inadequate design of the system as a whole, rather than specific scenarios in isolation. Such inadequacies, e.g. flawed links, can exist for a brief moment in time in the correct context, yet distant to each other in a different time and context. This can, however, be enough to cause an effect that is nonlinear, such as small events or conditions which can cause serious consequences (19); the reverse is also true. Therefore, the modern paradigm of systems thinking is more appropriate. The systems approach accentuates the importance of nonlinear interactions between system components and the system structure and mental models that determine it (20).

This paradigm is taken up by safety research in the maritime industry. It is observed that safety related research in the marine industry points towards further appreciation of the organisation, inter-organisational, and human aspect of the problem (21-24). Such research also points to the importance of not analysing barriers in isolation, but rather applying an appreciation of the entire system, and the interactions between its components, being of critical importance when analysing the emergence of 'safety' as a condition. While this wider safety research does not directly relate to fire safety in machinery spaces, its application may provide holistic improvements in fire safety in ships, which would ultimately include the machinery spaces. This systematic approach to accident prevention is not at the expense of analysis of individual features of fire prevention however and can be noted in the literature covering human and organisational factors, historical causal factors of fires in maritime transportation, calculation of fire probability (25-27), along with fire impact analysis research focusing on mitigating the outbreak of fire (28-41).

With the above in mind, the question is whether the prior assumptions that guide accident analysis, safety rules and regulations, etc. are indeed flawed. And if so, then we should not expect effective preventive or/and mitigation of fire events. To answer this question, we analyse the current approach to fire safety, identifying its focus along the line of accident development. We specifically analyse the current rules and regulations and their development biases, as well as biases in accident analysis and safety systems offered on the market. We then discuss the implications, the significance of these biases in view of the realities discussed above. Ultimately, this study looks to evaluate the effectiveness of the current approach to fire safety in machinery spaces in the maritime industry while considering where current safety research suggests the focus should lie.

The current approach to fires in machinery spaces is hypothesised to be reactive in nature, primarily focusing on detection of already materialised hazards such as flammable oil leaks or mist, unprotected high temperature surfaces $\left(>220^{\circ} \mathrm{C}\right)(42)$, and ignition or explosion itself. This research aims to analyse the focus to verify the hypothesis. 


\subsection{Organisation}

The paper is organised as follows. Section 2 details the method which has been applied with respect to the approach and how the results are classified. Section 3 presents the data gathered from the various facets of fire safety and general safety, while Section 4 discusses the results. Section 5 presents a discussion of the results considering the hypothesis and presents some possible improvements which can be investigated further. Section 6 concludes the analysis with acknowledgements in Section 7.

\section{Method}

\subsection{Approach}

We determine the focus of the current approach to fire safety by identifying the bias, if any, of the primary facets of fire safety, specifically:

- Current safety rules and regulations (IMO'1 , Classification Societies, Administrations);

- Studies of formal safety assessment (FSA), i.e. recommendations for new safety rules;

- Accident investigation (sample of recommendations from recent investigations);

- Technology currently aimed at fire safety, Dynamic Barrier Management (DBM)

The biases are determined by classifying the safety strategies within each constituent in subcategories of prevention and mitigation, as explained in the following section. It is important to note that while the analysis focuses on fire safety onboard, fires in machinery spaces is of special interest due to the increased number of fire incidents here.

Omitted from the analysis is an examination of the current 'best practices' which may be applied by individual companies which are used in conjunction with the rules applied from regulatory or governing bodies. Also excluded from the analysis are underlying factors which may still have an impact on fire safety, for example the effect of political pressures, global economy, any assumptions behind FSA implementation or results etc.

\subsection{Classification}

Prevention and mitigation form the two primary strategies associated with loss prevention, but they can be subdivided into more specific, and hence useful, sub-categories. It is important in the context of this paper that the commonly used terms of 'accident' and 'incident' are defined. An accident is defined as an unforeseen event that develops to result in serious consequences/ losses (property damage, injury, fatalities). An incident is an unforeseen event resulting in minor consequences, but which could escalate to an accident (43). In this paper this incident is an ignition of a fire event.

Hollnagel provides five possible strategies for loss prevention (44), namely replacement (failed component, subsystem etc.), prevention, facilitation (e.g., simplification or redesign of a task), protection (as means of mitigation or recovery), and elimination. Leveson et al. go one step further and proposed the impact scale for hazard mitigation strategies (21). They suggested similar categories for safety strategies: elimination (impact level 4), prevention (level 3), control (level 2), and damage reduction (level 1). By "control", the authors refer to reduction in the

\footnotetext{
${ }^{1}$ International Maritime Organisation (IMO)
} 
likelihood that the hazard results in an accident, i.e. the incident develops into an accident. Damage reduction would be mitigation of the consequences when the incident (ignition) occurs. The assignment of the impact level reflects the logic described earlier in the introduction, e.g. the elimination has the biggest impact because it removes all opportunities for damage. Thus, the bigger the impact with respect to loss prevention, the greater the strategy's effectiveness. This approach has been applied in other recent work (45) and is adopted in this paper to provide a guide to the effectiveness once the current focus is established.

For the analysis to be more informative, we classify the prevention category into four subcategories, focusing on eliminating a hazard, preventing systemic, contributing, and direct causal factors, as shown in Table 1. These subcategories correspond to Johnson's three-level model of accidents, which assumes that systemic causal factors give rise to contributing factors, which in turn, allow the direct factors (a.k.a., proximate or immediate events) to trigger an incident (46).

With respect to the level of effectiveness $(E)$, we introduce the linear scale of effectiveness such that $E$ can be reflected explicitly_as opposed to being used tacitly $(45,47)($ Table 1$)$. We assume basic increments of increased effectiveness ranging from 1-6, with the strategy for hazard elimination having the greatest effectiveness $(E=6)$, ranging to the lowest effectiveness level of damage limitation $(E=1)$, where consequences are difficult to predict, and we are in the so called 'last line of defence'. It is important to note, elimination may not always be possible (e.g., replacing flammable materials in the engine which requires combustion) but is included as a strategy for consistency.

It is noted there will be a cost implication on the strategy developed and applied, however this is out with the scope of this analysis. Further work on a detailed Quantitative Risk Analysis (QRA) could provide a benefit in validating cost benefit values associated with individual barrier elements, and subsequent cost effectiveness. 
Table 1: Strategies for loss prevention

\begin{tabular}{|c|c|c|c|c|}
\hline Focus & $\begin{array}{l}\text { Strategy } \\
\text { category }\end{array}$ & $\begin{array}{l}\text { Safety } \\
\text { function }\end{array}$ & Example barrier systems & $\begin{array}{l}\text { Effectiveness } \\
\text { level (priority } \\
\text { scale) (E) }\end{array}$ \\
\hline \multirow{4}{*}{ 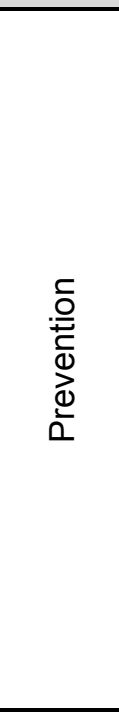 } & 1 & $\begin{array}{l}\text { Eliminate } \\
\text { hazard }\end{array}$ & $\begin{array}{l}\text { Decisions at concept and detailed design } \\
\text { stages (based on risk assessment, tests, and } \\
\text { other studies): substitution, simplification, } \\
\text { decoupling, replacement, etc. }\end{array}$ & 6 \\
\hline & 2 & $\begin{array}{l}\text { Prevent } \\
\text { systemic } \\
\text { factors of } \\
\text { incident }\end{array}$ & $\begin{array}{l}\text { Strong safety culture, effective inter- } \\
\text { organisational links, industrial best practices, } \\
\text { robust safety assessment methodology, } \\
\text { flawless standards and practices and } \\
\text { regulatory oversight }\end{array}$ & 5 \\
\hline & 3 & $\begin{array}{l}\text { Prevent } \\
\text { contributing } \\
\text { factors of } \\
\text { incident }\end{array}$ & $\begin{array}{l}\text { Safety management system (SMS), clear } \\
\text { communication and responsibilities and roles, } \\
\text { crew training and supervision, adequate } \\
\text { manning, fire drills }\end{array}$ & 4 \\
\hline & 4 & $\begin{array}{l}\text { Prevent direct } \\
\text { factors of } \\
\text { incident }\end{array}$ & $\begin{array}{l}\text { Passive and active safety systems (thermal } \\
\text { insulation, leak prevention, condition } \\
\text { monitoring, etc.), and their inspection and } \\
\text { maintenance actions }\end{array}$ & 3 \\
\hline \multirow{2}{*}{ 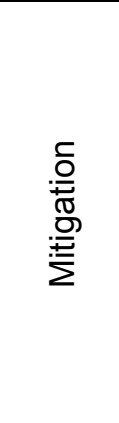 } & 5 & $\begin{array}{l}\text { Control } \\
\text { accident } \\
\text { (stopping from } \\
\text { propagating to } \\
\text { loss) }\end{array}$ & $\begin{array}{l}\text { Management decisions (training, staffing, } \\
\text { preventive maintenance etc.), automatic } \\
\text { detection and suppression systems, } \\
\text { emergency shutdown, ventilation control } \\
\text { system etc. }\end{array}$ & 2 \\
\hline & 6 & $\begin{array}{l}\text { Reduce } \\
\text { damage (loss) }\end{array}$ & $\begin{array}{l}\text { Management decisions (training, staffing } \\
\text { etc.), containment (structural fire protection, } \\
\text { fire doors etc.), automatic and manual } \\
\text { firefighting equipment and preparedness, } \\
\text { evacuation equipment and preparedness }\end{array}$ & 1 \\
\hline
\end{tabular}

In cases where a specific safety measure (e.g., a fire suppression system) fits into more than one safety category (e.g., fire safety technology, which applies to damage reduction and incident control), it will be assigned the effectiveness value of the most effective category, thus rewarding the benefit of an earlier approach. Table 1, and hence the results, can also be mapped to a 'bowtie' diagram $(48,49),(50)$. The bowtie reflects the progress towards an incident and as this analysis of effectiveness directly applies to the timeline of when the controls are implemented, where the strategy sits on the bowtie provides a visual reflection of the effectiveness. While the bowtie can hide complexity as it does not contain information on barrier type or system (Physical, Functional, Symbolic, Incorporeal), or account for the system as a whole and the interactions between various system actors, this study does not deal with specific barriers such as those presented by Saleh (51). The bowtie therefore serves as a means of communicating barrier categories along the timeline of events. This assists in this analysis, presenting where the focus lies with respect to fire safety. The accuracy of the bowtie as a risk analysis method is not in the scope of this paper and is solely applied as a visual representation on where the categories from Table 1 would sit.

Figure 2 shows this generic representation of the bowtie, with preventative measures applied to the left of the centre and mitigating factors, post ignition, carried out to the right. 


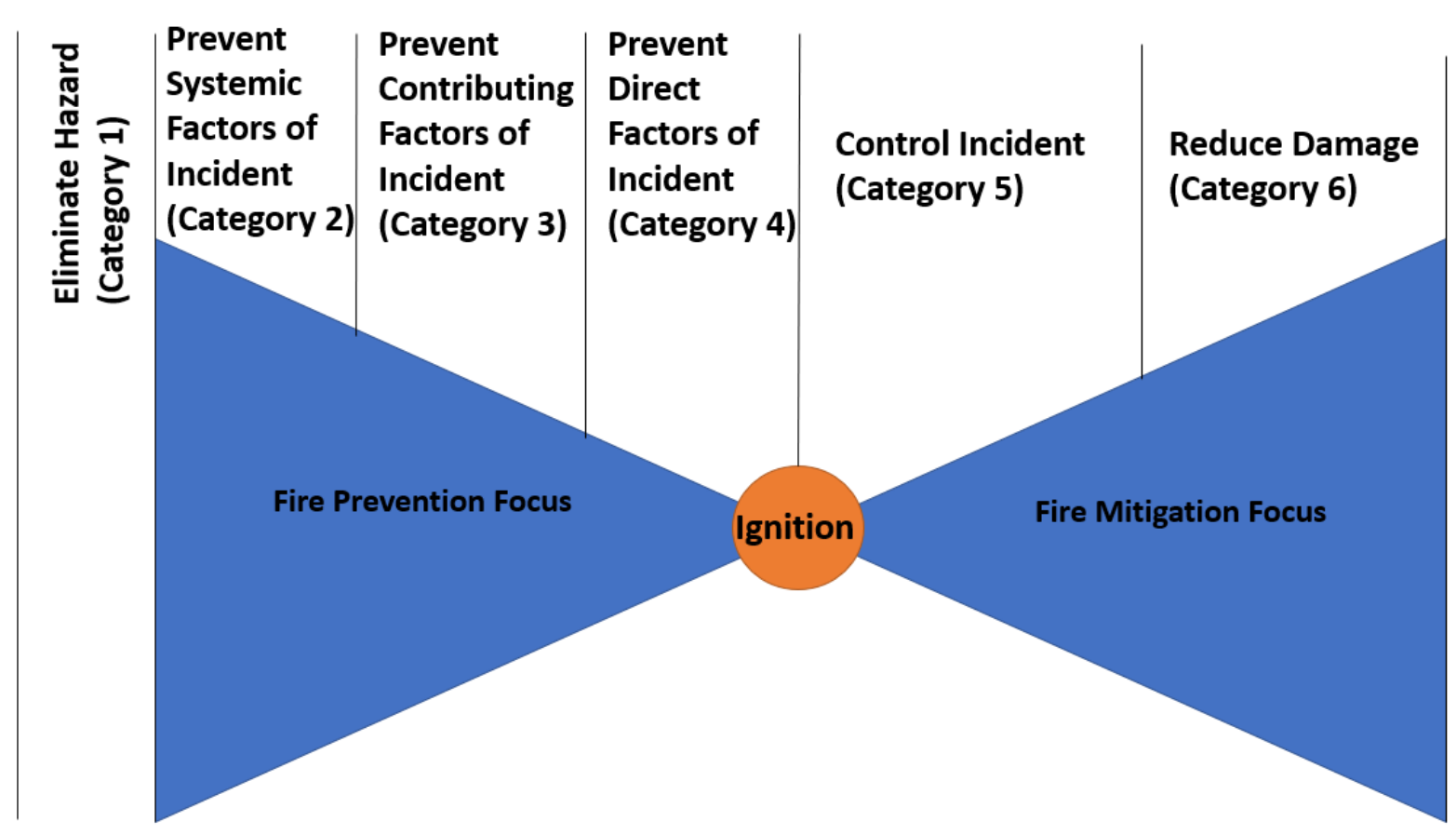

Figure 2: Focus on prevention/ mitigation

As we map the discrete category intervals from Table 1 onto the bowtie, we implicitly assume that the effectiveness is continuous and decrease linearly from the left to the right within each interval. Thus, improvements in safety barrier systems at the boundary between Category 4 and 5 (e.g., smoke detection and early fire suppression) would be more effective, and hence preferable, than those between Category 5 and 6 (e.g., emergency shutdown).

\section{Analysis}

\subsection{Safety rules and regulations}

In 2001, the IMO released Guidelines on Alternative Design and Arrangements for Fire Safety $(52,53)$. This document lays out the method by which engineering analysis can be carried out in complying with the performance-based fire safety requirement of SOLAS Chapter II-2. The guide refers to examples such as the SFPE Engineering Guide to Performance Based Fire Protection Analysis and Design of Buildings (54). This guide discusses implementation of inherently safer design and verifies that building design will function as intended in the event of a fire, starting from the assumption of fire presence, rather than focusing on the prevention of a fire in the first instance. The focus is therefore more strongly placed in the mitigation phase of fire incident control (Categories 5 and 6), detecting fire early and protecting the ship against propagation of the event.

In 2009 the IMO produced a document intended to harmonise the design practices to reduce fire in high risk areas on ships in the Guidelines for Measures to Prevent Fires in Engine Rooms and Cargo Pump Rooms (42). Particular attention was given to the lifecycle of areas which process flammable oils. The guidance aims to remove as far as possible the fuel from the fire triangle, providing recommendations like applying spray shields, applying jacketed piping systems where high-pressure streams exist etc. Also covered is the protection of hot surfaces where a flammable material may be present. The focus of this is clearly fire 
prevention, as the strategy focuses on preventing the propagation of precursors from developing into an accident. This would be classed as a prevention-based focus in Category 4 with respect to Table 1. These recommendations are also included in SOLAS Chapter 2, Regulation 4 (55), calling for the means to control leaks of flammable liquids, limit the accumulation of flammable vapours, restrict combustible materials, restrict ignition sources, separate ignition sources from materials which would ignite, and to eliminate an explosive atmosphere in the cargo tanks.

The IMO's Guidelines on implementation of the International Safety Management (ISM) Code (56) is intended to be an international standard on safe operation and management of ships. The code mandates a Safety Management System (SMS). The main, but not sole, focuses of the Code is the control of hazards where possible, accounting for human factors, and the prevention of incidents through improved safety management and operations (Categories 2 and 3 respectively). The ISM code also covers emergency preparedness which can contribute from the moments of ignition through to damage limitation, which covers Categories 4-6. This shows a broad focus of the ISM Code from Category 2 - 6.

Regarding guidelines available in reference to specific technologies in relation to fire safety, the IMO Fire Safety Systems (FSS) Code (57) was put in place to advise on strategies of incorporating fire detection and protection systems. This is another indicator of where safety rules and regulations focus, specifically on detection at the right of centre of the bowtie. The document discusses application of technologies used in the mitigation of ignition, principally falling under Category 5.

Another document with a similar focus is ISO14520-1:2015 providing guidance on gaseous fire extinguishing properties and design (58). The intent of the document is to maintain a minimum standard of extinguishing practices and, therefore, shows the mitigation focus of the guidance. It is credible that such systems could be used to cool exposed hot surfaces and therefore be a preventative measure in cooling the hot surface (such that if flammable material is released it will not contact with an exposed high temperature surface causing the ignition), but this is not the primary intent of the guidance, therefore it is assigned as a Category 5 fire safety guide. In order to apply such a system in a preventative based manner, a cost benefit analysis of the processes and procedures involved in activation would likely be required. This is, however, out with the scope of this paper.

Functional safety guidance can be applied in preventative efforts for applications such as ship engine rooms, despite being primarily focused in the process sector (59). This guidance focuses primarily on the reliability and design of safety instrumented systems which can be used to detect accident precursors and prevent failures. This is of relevance in engine room fire prevention with machinery failures presenting a notable precursor to fire. This guidance focuses within Category 3, although does branch into probability of incident detection which moves into Category 4 . The document also provides guidance on the elimination of systematic failures during design, and the importance of risk assessment in the elimination or control of hazards. This provides us guidance focused in Category 2.

The IMO (60) also provide guidelines on evacuation analysis on passenger ships which, although relating to a multitude of safety issues, presents a significant mitigation function in the case of a fire - the removal of humans who could be harmed. This guidance therefore falls within category 6 , relating to the reduction of losses. 
According to Lloyd's list (61), the top four shipping classification societies in 2017 were DNVGL, ClassNK, ABS and Lloyds Register. When analysing Class requirements, these societies shall be analysed with respect to the guidelines available from them (62-67).

The DNVGL rules and guidance provide a reference directly back to SOLAS Chapter 2. Fire prevention measures are limited to those covered under this SOLAS reference. Beyond this, there are some specific requirements with respect to preventing oil leakage and ignition from exposed hot surfaces, structural requirements, fire suppression/protection requirements and means of escape, clearly focused on Categories 4-6 from Table 1.

The guidance provided by ClassNK focuses very much on fire control. The guidance presented on integrated fire control systems focuses on detection of fire, and ventilation systems to control smoke - Category 5 recommendations. The document, however, does discuss countermeasures to prevent ignition from releases of flammable materials, falling under Category 4.

ClassNK also presents guidance on fire protection systems, of which reference is provided to the IMO guidelines on the maintenance and inspection of fire protection systems and appliances (MSC.1/Circ.1432 and MSC.1/Circ.1516) which are stated as ClassNK's minimum guidelines. The document includes a chapter on probability of ignition, where control of hot surfaces and releases of flammable materials are discussed, providing Category 4 recommendations. This chapter is, however, followed by 21 chapters specifically related to mitigation measures including fire detection, suppression and means of escape - Category 5 and 6 recommendations. While focus exists on preventative measures, most of the class rules relate to mitigation measures related to fire falling under Category 5 and 6 guidance.

American Bureau of Shipping (ABS) presents guidance on the extinguishment of a fire and presents various classifications of fire for consideration when designing the overall protection system. The main bulk of the guidance focuses very much on fire suppression requirements including guidance on fixed gas, water and foam fire extinguishing systems, falling under Category 5 recommendations. The guidance does, however, contain additional fire protection requirements which could be classed as preventative, when it discusses the segregation of hot surfaces and flammable materials, separation of pressurised processes, material requirements to avoid ignition and insulation of hot surfaces which could present an ignition source - Category 4 recommendations.

The guidance provided by Lloyd's Register details fire safety related factors such as active fire protection systems, structural protection, emergency shutdown measures in the presence of fire, and fire response measures. The guidance provides focus on reviewing how fires will escalate and what barriers are adequate in fire containment and mitigation, falling under Categories 5 and 6.

From the analysis it is apparent that the regulations and class requirements guide towards both prevention (Category 2-4) and mitigation (Categories 5 and 6). It is notable, however, that the preventative attempts are those which are principally reacting to a failure which has already occurred in the most part, e.g. a release of flammable oil, as opposed to the prevention of such failures in the first place. In the case of machinery spaces, failing to account for earlier prevention of precursors to those incidents could explain most fires being caused by the same 
direct causal factors, which the regulations and class rules aim to prevent/ mitigate at the sharp end.

Guidance relating specifically to fire safety, as discussed in this section, is somewhat separate from inherently safer design of machinery (i.e. Categories 1-4), for example, which is in place to prevent some of the events which could lead to fire (i.e. break in containment). Documentation addressing loss prevention in machinery spaces, although not specifically specified for the marine industry, includes BS EN ISO 12100:2010 (68), which provides guidance in complying with the Machinery Directive 2006/42/EC of the European Parliament and Amending Directive 95/16/EC (69), within which seagoing vessels are excluded. The guidance and directive discuss factors that designs should take account of and have been known to contribute to fires in the past. As this is generally left to previous experience or knowledge of what has gone wrong before, this emphasises the importance of accident investigation during design, which will be addressed later in this paper.

\subsection{Formal Safety Assessment (FSA)}

In the aftermath of the Piper Alpha disaster in 1988, a review of the safety regime and practices was triggered towards a more systematic (scientific) and proactive approach for their development, in view of established practices-such as probabilistic safety assessment-in nuclear, aeronautic and other industries. In 1993 the UK Maritime and Coastguard Agency (MCA) submitted a five-step procedure for safety analysis called Formal Safety Assessment (FSA) (70), with the IMO adopting interim FSA guidelines and starting trials in 1997. FSA is generally accepted in the industry now. Initially intended for IMO committees and maritime administrations, it is now used by classification societies for development of classification rules (9).

The FSA guidelines outline a systematic process of assessing different risks and risk control options (RCOs) or safety barriers (48), and provide guidance on cost benefit analysis of RCOs $(70,71)$. The FSA process fundamentally implies the quantitative assessment of risks and safety barriers through the probabilistic framework. The quantification of risks is essential for cost benefit analysis, i.e. determining if a proposed RCO is cost effective with respect to a quantitative criterion. If this can be taken as the current method, as stated by Goerlandt (2, 72), its focus can be determined by reviewing its results, i.e. the proposed safety barriers in the context of fire safety in machinery spaces.

This paper investigates the FSA carried out as part of the SAFEDOR project (73). The assessments focused on cruise ships and Ro-Ro passenger ships $(74,75)$. Another recent source where the FSA process has been applied is the FIRESAFE project (76). The project was aimed to develop safety barriers against fires on Ro-Ro passenger ships, with exclusive focus on vehicle decks. Although the focus was not on machinery spaces, we argue that the study is indicative of the current approach to fire safety and hence is useful for our analysis. This FIRESAFE project was followed up in 2018 with FIRESAFE II (77), the results of which are also presented.

The proposed RCOs across the three studies include the installation of oil mist detectors, monitoring of hot surfaces, electrical connection boxes, use of ship cables and adaptors, IR cameras etc. (Category 4 recommendations), along with Category 5 and 6 recommendations including rolling shutters, freshwater activation, CCTV systems and evacuation optimisation 
systems. The only preventative finding in categories 1-3 related to training, to increase awareness - a category 3 recommendation.

Table 2 highlights all RCOs recommended on Cruise Ship applications under SAFEDOR, and RoRo passenger ships under both FIRESAFE projects (FIRESAFE I and II RCOs are noted as FS). Titles of RCOs have been extracted directly from the reports, so any ambiguity of title is carried forward. Grouping has, however, been determined based on the RCO descriptions. Where RCOs are applicable to more than one category they are listed multiple times.

Table 2: Risk Control Options (RCOs) recommended (73) (76) (77)

\begin{tabular}{|c|c|c|}
\hline Focus & Safety function & Risk Control Option (RCO) \\
\hline \multirow[b]{4}{*}{ 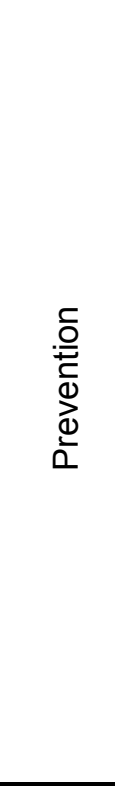 } & Eliminate hazard - Category 1 & $\bullet$ \\
\hline & $\begin{array}{l}\text { Prevent systemic factors of incident } \\
\text { - Category } 2\end{array}$ & - $\quad-$ \\
\hline & $\begin{array}{lll}\text { Prevent contributing factors of } \\
\text { incident }- \text { Category } 3\end{array}$ & - Training for awareness (FS) \\
\hline & $\begin{array}{l}\text { Prevent direct factors of incident - - } \\
\text { Category } 4\end{array}$ & $\begin{array}{ll}\text { - } & \text { Installation of oil mist detectors } \\
\text { - } & \text { Temperature monitoring (of hot surfaces?) } \\
\text { - } & \text { Key-card system to turn on el-system in cabin } \\
\text { - } & \text { Mandatory FM-Class } \\
\text { - } & \text { Laundry exhaust ducts } \\
\text { - } \quad \text { Correct maintenance in Engine Room } \\
\text { - } \quad \text { Robust connection boxes (FS) } \\
\text { - } \quad \text { Only ship cables (FS) } \\
\text { - } \quad \text { IR Camera (FS) } \\
\text { - } \quad \text { Unly crew connections (FS) } \\
\text { - } \quad \text { Correct maintenance in Engine Room } \\
\end{array}$ \\
\hline \multirow[t]{2}{*}{ 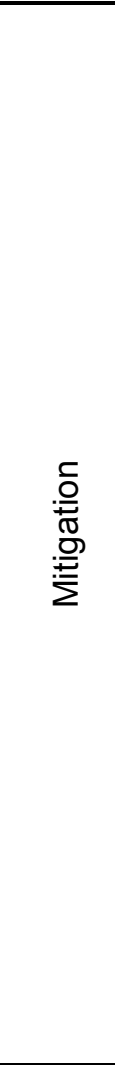 } & $\begin{array}{l}\text { Control accident (stopping from } \\
\text { propagating to loss) - Category } 5\end{array}$ & $\begin{array}{ll} & \text { Better emergency training of crew } \\
\text { - } & \text { Automatic shutdown of fryers } \\
\text { - } & \text { Open decks fire detection and suppression } \\
\text { - } & \text { Mandatory FM-Class } \\
\text { - } & \text { Combined heat \& smoke detection (FS) } \\
\text { - } & \text { Remote control (FS) } \\
\text { - } & \text { Eolling shutters (FS) } \\
\text { - } & \text { Fresh water activation routines (FS) } \\
\text { - } & \text { CCTV (FS) } \\
\text { - } & \text { CCTV \& remote release (FS) } \\
\text { - } & \text { Increased frequency fire patrols (FS) } \\
\text { - } & \text { Alarm System Design \& Integration (FS) } \\
\text { - } & \text { Preconditions for Early Activation of Drencher } \\
& \text { System (FS) } \\
\end{array}$ \\
\hline & Reduce damage (loss) - Category 6 & $\begin{array}{l}\text { - } \quad \text { Better emergency training of crew } \\
\text { - } \quad \text { Self-illuminating lights } \\
\text { - } \quad \text { Evacuation notification system } \\
\text { - } \text { Outdoor stairways } \\
\text { - } \quad \text { Regard sundeck as a public space } \\
\text { - } \quad \text { Ventilation systems in corridor } \\
\text { - } \quad \text { Combustible material requirements* }\end{array}$ \\
\hline
\end{tabular}




\begin{tabular}{|l|l|r|}
\hline Focus & Safety function & Risk Control Option (RCO) \\
\hline & $\begin{array}{l}- \text { Ban / closure of side \& end openings (FS) } \\
\text { Improved markings/signage for wayfinding and }\end{array}$ \\
& $\begin{array}{l}\text { localization (FS) } \\
\text { Safe distance (FS) }\end{array}$ \\
\hline $\begin{array}{l}* \text { This has been placed in both mitigation categories as the combustible material requirement description is not fitting of } \\
\text { preventing an ignition, but rather preventing spread of a fire throughout the ship and limiting the damage a developed fire } \\
\text { can cause. }\end{array}$ \\
\hline
\end{tabular}

\subsection{Accident analysis and recommendations}

Accident investigation aims to understand accident causation and provide the main basis for changes in design and operational practices (26). Accident analysis, therefore, plays the key role in safety improvement. Here we and look at a small sample of recent fires in machinery spaces to provide a more detailed overview, despite being a limited sample.

In analysing the current approach to safety, Schröder-Hinrichs et. al. (78) discuss the analysis of 41 accident investigations relating to fires/ explosions in machinery enclosures. The results of this study provide a broad view of where the recommendations focus. Schröder-Hinrichs et. al. concludes that, considering the expectations of the IMO guidelines with respect to accident investigations, organisational factors were not adequately addressed. Their findings show that a large percentage of the stated accident causes related to technological failures and failed physical safety barriers, focusing on causation linked to Category 4 . The finding is further demonstrated by Rollenhagen (79) in that there is a lack of attention to the organisational context in which an accident investigation is taking place, demonstrating a lack of appreciation for Categories 2 and 3. Further evidence of a limited application of systemic causal factors in accident investigation is shown by Puisa $(80,81)$.

Highly populated databases such as the European Marine Casualty Information Platform (EMCIP) present causation statistics, but refer to accident causation in generic terms such as 'Human Erroneous Action' or 'Equipment Failure' (82). As these details are high level, extracting the recommendations from accident investigations from these statistics, despite having a vast number of accidents included, will not present data on the specific accident causes and subsequent recommendations which are detailed in the reports. To demonstrate the current focus of accident investigation, we therefore briefly review three recent fires in machinery spaces, highlighting the determined causes and the recommendations made.

\section{Le Boreal}

On 18th November 2015 a fire broke out in the engine compartment on board the ExpeditionCruiser Liner Le Boreal (83). The accident investigation concluded that a spray of oil contacted a turbo blower exhaust elbow and ignited. The report presented that the release had been caused by an engineer replacing a clogged filter on a diesel generator duplex filter believed to be isolated. The recommendations included the alteration of maintenance procedures (Category 4), exploration of the value of segregating $\mathrm{HFO}^{2}$ and $\mathrm{MDO}^{3}$ circuits feeding the engine to simplify maintenance (Category 3 ) and to review the effectiveness of radio communication during firefighting (Category 5/6). This shows a focus both on prevention and

\footnotetext{
2 Heavy fuel oil

${ }^{3}$ Marine diesel oil
} 
mitigation with Categories 3-6 featuring. However, the primary emphasis focuses on the proximate, direct causes and response.

\section{Zenith}

On 25th June 2013, the MV Zenith had a fire between the turbocharger and cylinder head in the engine room (84). The immediate cause of the fire was deemed to be a fracture of a low carbon steel pipe (a result of fatigue) which led to the release of flammable material spraying onto an exposed hot exhaust gas manifold.

The report recommended risk assessing machinery spaces to identify critical equipment, such that it could be implemented in the ship's maintenance routine (Category 4). As this risk assessment appears to focus on including equipment in the maintenance routine (prevention through planning), rather than eliminating a hazard, it has been included in Category 4 only. The recommendations focused on prevention of proximate events immediately before ignition.

\section{Sea Gale}

On 20 May 2014 the crew supply vessel Sea Gale experienced a fire at a carbon composite panel and insulation area above the main engine exhaust pipe (85). The investigation concluded that ignition likely occurred through overheating of the panel due to the radiating heat from the exhaust pipe, with contributing low ventilation conditions.

The report states that several 'preventive' measures are being placed including a review of manifold, exhaust pipe and funnel insulation (Category 4), along with better implementation of emergency buttons and quick closing valves (Category 5). Some operational improvements are also highlighted, with a checklist for main engine start up to provide increased airflow prior to start up, with additional reporting requirements when this is complete, and amendments to procedures for supervision/approval of works going on at shipyards. These fall within Category 3 recommendations. Improvements in training to improve emergency response is also included, proving a Category 5 recommendation.

Analysis of these three sample fires shows that most recommendations are preventative, with some mitigation-based recommendations (Categories 3-6). The overall findings relating to prevention and mitigation are all, however, close to the centre of the bowtie. This is in line with the analysis of a large set of accident investigation reports of fires in machinery spaces (78).

\subsection{Fire safety systems}

When considering barriers to be implemented to increase safety, technology-based barriers are often a perceived quick and easy fix to increase safety (86-88). Such fire safety systems range from the application of instrumentation based technological safety systems, to passive structural measures designed into the ship (fire walls, blast walls etc.). To determine the focus of technology we must analyse the current technologies used in addressing fire safety in machinery spaces.

The drive towards improved fire detection began with traditional smoke/heat detection, providing fast response detection of fire to improve response in the event of a fire. Such technologies have evolved to detect more than just fire, with some being used to highlight the presence of fire precursors (i.e. hot surfaces) using temperature sensing cable products (89). 
In 2004 the first 5th generation fire alarm system was supplied to the shipping industry, using intelligent sensors, interconnected as an analogue addressable system (90). Such technologies reside within Categories 4 and 5 as per Table 1.

DNV state that $63 \%$ of fires start in the engine room, primarily due to oil leaks (5). Oil mist detectors, available as either a point (91), open path (92), or aspirating device (93), have therefore risen in prevalence as potentially suitable technologies in detecting proximate events/ precursors of fires in engine rooms (Category 4). In 2003 the IMO released MSC/Circ.1086 (94), a code of practice for the application of oil mist detectors which further highlights their importance as a fire safety related technology. Such devices reside within Category 4.

Application of CCTV based imaging devices present a potential solution with respect to detection of flammable releases within the area of concern. Imaging devices may be applied to detect the release of flammable mists/ volumes of gas through Gas Cloud Imaging (95), in addition to elevated temperatures of specific high risk pieces of equipment (96). The focus of this technology is clearly on proximate precursors to fire in Category 4.

Instrumentation monitoring the internal flow, pressure, and temperature of equipment feed lines may present information on potential leaks and releases which could act as a precursor to a fire. Should these systems be installed in pre-determined high-risk pieces of equipment, they can provide alarms signalling precursors to loss of containment, a major precursor to fire (Category 4). Pressure, flow and temperature transmitters could be a credible solution to detecting and acting on fire precursors and are currently readily available. At the time of writing, however, there is little data to suggest the widespread application of these safety instrumented systems in engine rooms with automated protection actions in the context of fire safety.

This analysis shows the focus of fire safety technologies related to prevention are focused on anomalies immediately left of ignition on the bowtie, falling under Category 4, with the mitigation-based technology carrying though Categories 5 and 6 . Technologies exist which can detect further left of centre on the bow tie (such as the safety instrumentation previously discussed), but it is unclear if these are applied with a focus on fire prevention. As an additional note, while detection and suppression are separate systems, both must operate as intended in order to achieve the required hazard control. When, for example, detection occurs, an action must be taken to mitigate the situation such as automated suppression, or mobilisation of the emergency response team. Both are independent, critical systems.

While this has demonstrated the focus of fire safety technology, Dynamic Barrier Management (DBM) is an emerging technique aimed at strengthening these barriers surrounding the centre of the bowtie. Through analysis of barrier health and overall risk to the system, DBM is generally applied before the incident, measuring performance at the sharp end of hardware (and perhaps software and people). There exists a limitation in how far left of the centre such a technique can be applied when there is a limitation on how safety facets (such as categories 2 and 3) can be 'measured', in real time. The data which can be directly measured can, however, be used to improve the interactions / decisions / assumptions to the far left of the bowtie. This emerging and important aspect of the system operating as a whole, addressing interactions from Category 1 through to 4 , will be discussed in Section 5. 
The following table summarises the focus of each available fire safety related technology applied in machinery spaces against the criteria of Table 1.

Table 3: Fire safety technology focus

\begin{tabular}{|c|c|c|}
\hline Focus & Safety function & Fire Safety Technology \\
\hline \multirow{4}{*}{ 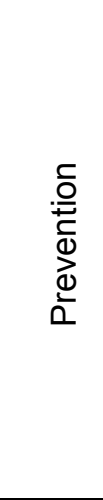 } & Eliminate hazard & $\mathrm{N} / \mathrm{A}$ \\
\hline & Prevent systemic factors of incident & N/A \\
\hline & Prevent contributing factors of incident & $\mathrm{N} / \mathrm{A}$ \\
\hline & Prevent direct factors of incident & 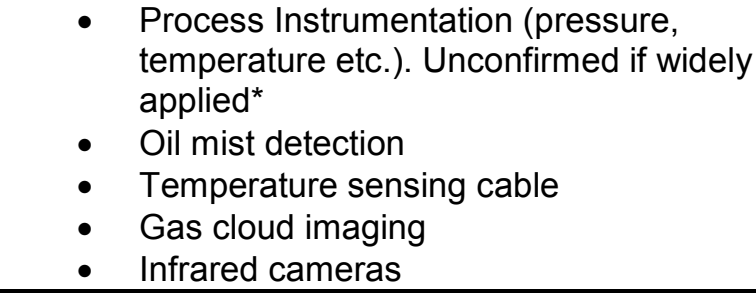 \\
\hline \multirow{2}{*}{ 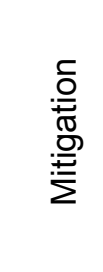 } & $\begin{array}{l}\text { Control accident (stopping from propagating } \\
\text { to loss) }\end{array}$ & $\begin{array}{l}\text { - Traditional smoke/ heat detection } \\
\text { - Optical flame detection } \\
\text { - Suppression systems }\end{array}$ \\
\hline & Reduce damage (loss) & $\begin{array}{l}\text { - Evacuation systems }{ }^{* *} \\
\text { - Passive protection measures (structural } \\
\text { arrangements) }\end{array}$ \\
\hline
\end{tabular}

*such systems may be applied for multiple reasons including equipment protection (to protect engine overspeed for example) as well as safety and may not specifically be applied under a 'fire safety' category.

${ }^{* *}$ Evacuation systems here refers to a multitude of systems including procedural systems (fire drills etc. as part of the SMS), and adequate signage, escape routes etc.

\section{Results}

Table 4 demonstrates the focus of the current approach with respect to fire safety. The values of effectiveness, as defined in Table 1, are shown under each constituent of safety control. The resultant effectiveness value (the maximum possible effectiveness relating to the approach) is shown for each constituent. 
Table 4: Summary of the focus of the current approach to fire safety

\begin{tabular}{|c|c|c|c|c|c|}
\hline Focus & Safety function & $\begin{array}{l}\text { Safety rules } \\
\text { and } \\
\text { regulations }\end{array}$ & $\begin{array}{l}\text { Formal safety } \\
\text { assessment }\end{array}$ & $\begin{array}{l}\text { Accident analysis } \\
\text { and } \\
\text { recommendations }\end{array}$ & $\begin{array}{l}\text { Fire safety } \\
\text { systems }\end{array}$ \\
\hline \multirow{4}{*}{ 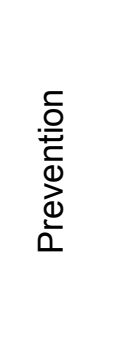 } & Eliminate hazard & $x$ & $x$ & $x$ & $x$ \\
\hline & $\begin{array}{l}\text { Prevent systemic factors of } \\
\text { incident }\end{array}$ & $\checkmark$ & $x$ & $x$ & $x$ \\
\hline & $\begin{array}{l}\text { Prevent contributing factors } \\
\text { of incident }\end{array}$ & $\checkmark$ & $\checkmark$ & $\checkmark$ & $x$ \\
\hline & $\begin{array}{l}\text { Prevent direct factors of } \\
\text { incident }\end{array}$ & $\checkmark$ & $\checkmark$ & $\checkmark$ & $\checkmark$ \\
\hline \multirow{2}{*}{ 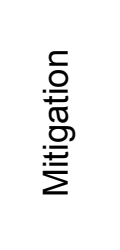 } & $\begin{array}{l}\text { Control incident (stopping } \\
\text { from propagating to } \\
\text { accident/loss) }\end{array}$ & $\checkmark$ & $\checkmark$ & $\checkmark$ & $\checkmark$ \\
\hline & Reduce damage (loss) & $\checkmark$ & $\checkmark$ & $\checkmark$ & $\checkmark$ \\
\hline \multicolumn{2}{|c|}{ Effectiveness (E) Value } & 5 & 4 & 4 & 3 \\
\hline
\end{tabular}

Key:

$\checkmark=$ The constituent of safety control does consider fire safety in this region of the bowtie. $x=$ The constituent of safety control does not consider fire safety in this region of the bowtie.

Mapping the analysis in Table 4 onto the bowtie, we can visualise the focus of the analysed constituents of safety control of the current safety approach and where they lie in the prevention and mitigation regions. Note, however the limitation exists that where one constituent extensively covers one specific region, for example mitigating an accident, and only briefly touches on another, for example preventing direct causes of an incident, the distinction between these varying degrees of emphasis is not specifically measurable in all circumstances. Credit is therefore conservatively assigned to both, with no differentiation between the two. 


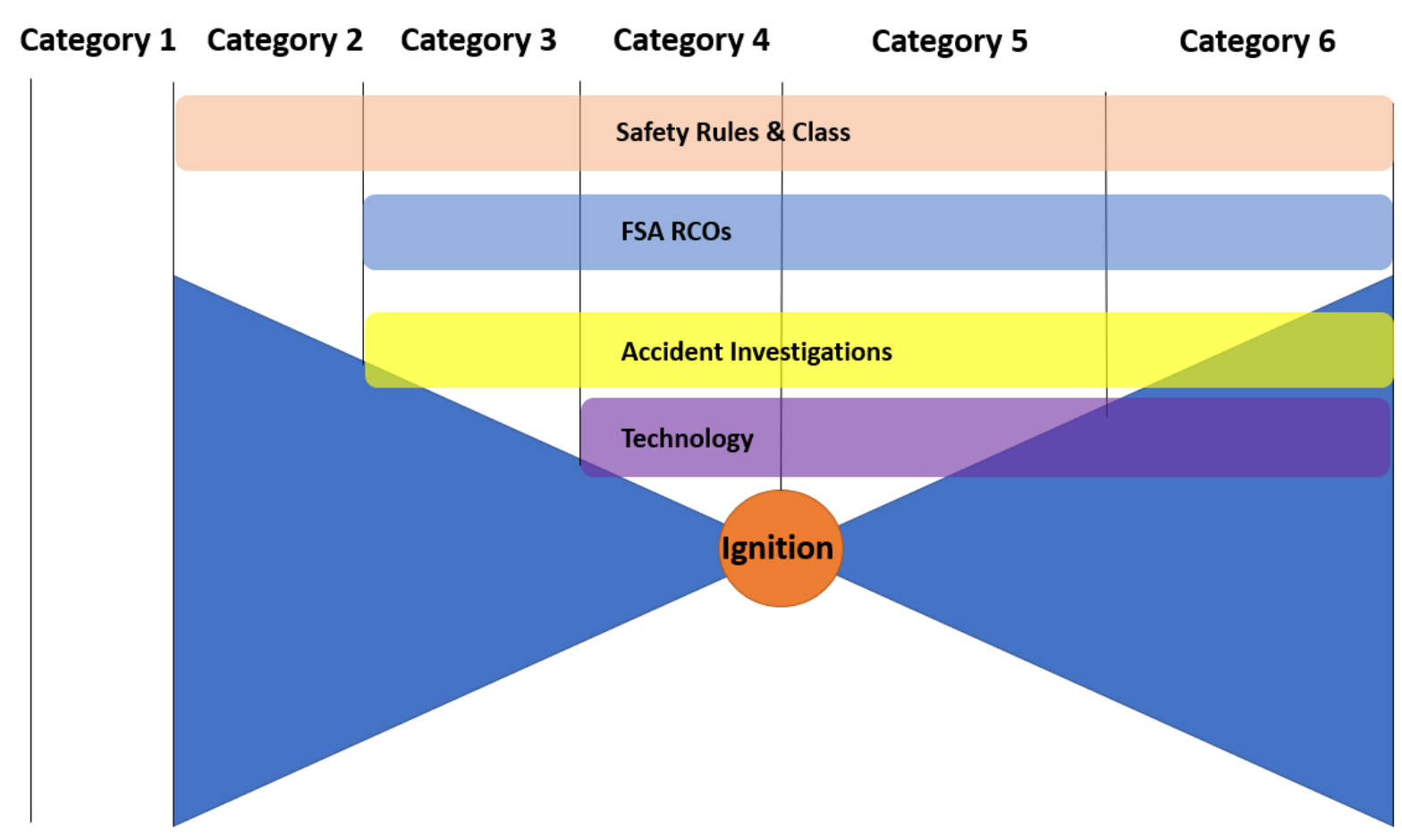

Figure 3: Bow tie of current fire safety focus

This figure demonstrates that FSA, accident investigation and technology present some scope to improve upon the preventative aspects and subsequently improve upon their inherent effectiveness, while safety rules and regulations cover the spectrum of prevention and mitigation from Categories 2-6.

With specific comment on FSA, the recommended RCOs with respect to machinery space fire safety relate to Categories 3-6. It is worth noting, however, that many of these preventative options relate to proximate precursors immediately before ignition (Category 4 ) and the focus appears predominantly towards a combination of Category 5-6 recommendations. It is also worth noting that only one out of 33 RCOs was left of Category 4, which provides an optimistically high effectiveness of 4 .

With respect to accident analysis and recommendations, the investigation reports regularly present recommendations to address SMS deficiency (Category 3 ) and proximate precursors immediately left of the bowtie, including insulation of exposed high temperature surfaces (Category 4) and improvements in the actions of first responders (Categories 5 and 6) in machinery spaces. This highlights the potential for accident investigation to focus on a bigger causal picture, looking for systemic causal factors beyond proximate events. This echoes a general critique of accident analysis for its bias to look for and stop at "root causes", which typically appear to be proximate individual failures (47).

When analysing the application of technology to fire safety in machinery spaces, Table 3 suggests that the use of preventative technologies is on par with mitigation aimed systems. This may be somewhat misleading, however, in addressing how far left these preventative technologies focus, shown in Figure 3. The guidance specifically relating to technology is weighted towards mitigation, with SOLAS Chapter 2, the class requirements, the FSS Code, ISO14520-1 etc. all focusing on application of mitigation focused systems. Where prevention is a focus, it is immediately before an ignition occurs, as is also reflected in the preventative 
technology guidance in SOLAS Chapter 2 regulation 4. The guidance which exists relating to preventative measures in the centre-left to far-left region of the bowtie (e.g., ISM Code) does not necessarily refer to technology. Concluding from this, there may be limiting factors in how far back in the bowtie technology can currently progress, which will be subject to discussion in Section 5.

\section{Discussion}

We have established the focus of the current approach to fire safety in machinery spaces. Taking a closer look at incident prevention, the bias towards direct causal factors may be attributed to the widespread application of linear, event-based models to accident analysis. Namely, sequential and epidemiological models, known by the Domino (97) and Swiss Cheese (98) metaphors. These models represent the classic paradigm of linear representation of causation, where clear links between causes and effects must be known, and system safety is assumingly improved by independent treatment of individual components of the system. Hence, the system is assumed as essentially a sum of its individual components. Although this linear paradigm has its own merits, it is insufficient to achieve system safety as shown in the literature $(21,22,45,48,86-88,99)$. The linear thinking focuses on incident events and their patterns-which are the visible tip of the iceberg-but systematically fails to explain the underlying structure and mental models that give rise to those events-the invisible, underlying portion of the iceberg (100). The underlying system behaviour cannot be changed by merely reacting to its events, or by analysing components of the system in isolation (17). The reason being that a system is more than the sum of its components (12). Therefore, the modern paradigm of systems thinking must be addressed. In addition to contribution to causation of individual components, the systems approach accentuates the importance of nonlinear interactions between them and the system structure and mental models that determine it (20). As a result, the accident analysis will naturally seek to answer not only what happened but also why it happened.

Such techniques do exist, including the SCAT chart - Systematic Cause Analysis Technique (101). This accident/ incident analysis technique attempts to address direct causes, as well as the basic/ underlying causes of events. Such an approach can however fall into the same trap of treating the failure as a linear series of events (102). There is little evidence in the recommendations from accident analysis that such a systematic technique is applied holistically in practice.

Another explanation of the bias towards proximate events lies in the final stages of accident investigation of machinery space fires, namely the development of recommendations. It is known that recommendations for remedial actions are often tailored to the existing capacity (of the shipping company) to implement them (103), and the focus on proximate events, such as recommending fixes to failed technical barriers, would be seen as the 'low-hanging fruit'.

To improve things further, the misconception of human error must be addressed. Human error at the sharp end is regularly cited as a cause of fire (104). It can be divided into two distinct categories of slips and mistakes $(105,106)$. A mistake is an error in the intention (the planning of an action), whereas a slip is an error in carrying out the intention. The machinery space fire on board Le Boreal was triggered by a slip (107), which are relatively easy to prevent, for example, by using different colour coding, warning signals, separation by distance, interlock, 
etc. Prevention of planning mistakes requires a more fundamental approach, for the errors are only seen as such in hindsight (47). It is suggested that the term human error should be replaced by considering such events as human-task mismatches instead (108). In general, human errors at the sharp and blunt ends are symptomatic of deeper underlying problems in the control of safety rather than the direct cause of accidents (23). Thus, the systems based approach may again be beneficial (109).

The literature would tend to suggest the ISM code intended to address such factors, while in its relative infancy, is limited in its application (78). This may also be true of other strategies, as the events close to the centre of the bowtie are generally those which have a higher degree of certainty (i.e. rupture of a pipe combined with exposed ignition source). As Category 4 and 5 are those closest to the centre of the bowtie, it would therefore be understandable if these categories were the most commonly applied strategies with respect to fire safety designers and technology applied. This analysis has shown that every facet of fire safety addresses these two categories.

It has also been shown, that when it comes to safety automation and technology, there exists a limit in how far back one can currently go in the bow tie in preventing machinery space fires. The available precursor detection technology (e.g., temperature sensors) focuses on proximate events because they are of relative ease to address in design and operation. Its effect on safety is also certain and observable, and hence such technology is easy to justify. However, dealing with more underlying causes such as contributing and systemic causes becomes problematic. The automation is not directly applicable to 'measuring' people, the organisation, procedures etc. Also, there is a general lack of knowledge about early, systematic fire precursors, a lack of a clear solution on how to deal with them, and difficulty in measuring performance of such safety barriers in place to prevent or mitigate such precursors.

The analysis of Dynamic Barrier Management (DBM) also shows us the importance of strengthening the technological barriers, but also the impact this can have elsewhere in the system, and the importance of addressing interactions throughout the entire left-hand side of the bowtie. To simplify this, applying DBM to the preventative technologies (i.e. oil mist detectors) does not move 'Fire Safety Technology' as a facet of fire safety any further left on the bowtie, but it can assist the barriers placed further left, therefore also strengthening them. DBM provides an improved feedback and control loop with respect to the sharp end barriers to the other controllers across and further up the hierarchy. An example of where this can be useful includes the application of a digital twin (DT), where a digital representation of a vessel or its part can have real time numerical assessments of a given situation carried out to assist with real time consequence analysis to improve holistic fire safety improvements.

Notable from Table 4, is the move right on the bowtie as we move from Safety Rules and Regulations, through FSA and Accident investigations and Technology (with the caveated discussion on technology above). One possible consideration for the marine industry is the integration and application of the current safety rules and regulations into all facets of fire safety. This could, in time, assist in reduce the consistent frequency in which fires in the machinery spaces continue to occur. If FSA and accident investigations can begin to account for the factors being advocated in the safety rules and regulations (along with improved feedback from the sharp end through DBM), an improvement in holistic fire safety is certainly credible. 
On reflection of the results and this discussion, the idea of treating the system as a whole may in fact provide an effectiveness metric itself. This analysis has potentially fallen into the trap as the current approach... treating each facet of fire safety individually by splitting these into categories and assigning effectiveness. This may not adequately address the effectiveness of the system and its interacting components. While this paper's objective is to determine the focus of fire safety, future work must investigate methods to focus on the entire system. While mitigation (Categories 5 and 6 ) begins from the assumption of a fire being present (likelihood of 1.0), preventative categories do not work in this way. The traditional approach of assigning effectiveness differences between Categories 1-4 as we do with mitigation may not be an accurate method of analysis when compared to an analysis of the entire system effectiveness (i.e. the ability of the system to account for all four preventative categories rather than each in isolation).

This further demonstrates that in order to design and operate an effective system, multiple approaches may have to be applied. Mitigation, where cost benefit analysis and FSA can more easily be carried out (as per the current approach), along with technological capabilities which allow mitigation barrier health to be monitored, can continue to apply a quantitative risk approach. When it comes to prevention, however, such an approach may need to be replaced with a systems-based approach which can only be effective when the entire left-hand side of the bowtie (for want of a graphical representation) is accounted for. This allows the operators to focus on the interactions between all of the actors in the system, rather than a reductionist view of safety being a sum of all the parts, leading to the criticised approach of adding more layers of barriers to 'increase' safety (17). The process under which FSA is conducted may therefore not be appropriate for prevention.

Applying a systematic approach is one in which the groundwork already exists, with SOLAS allowing for alternative design arrangements with respect to fire safety (55). With the ability to address alternative design arrangements, we move towards a goal-based approach which requires designs to set functional requirements allowing designers the freedom to meet those requirements in any number of ways. With the move away from prescriptive guidance, this provides the scope for the marine based fire safety industry to expand from a focus as shown in Figure 3, towards addressing prevention more thoroughly and effectively as a complete system.

\section{Conclusions}

This paper has raised the question of where the current approach to fire safety in machinery spaces focuses, and whether it is effective. To answer it, we have conducted an analysis of current industrial practices and academic interests concerning fire safety in the maritime sector. During the analysis, we used specific criteria for inferring the focus and subsequent effectiveness of analysed safety rules, regulations, recommendations and technologies. The results show that the effectiveness of the current safety measures used in practice may be suboptimal, with the focus being placed on the detection of proximate events immediately prior to ignition, and on the mitigation of post ignition events.

To improve the effectiveness of the current approach to fire safety in machinery spaces, we recommend investigation of the adoption of a more systemic, holistic approach to fire safety at sea with an expanded effort towards prevention further left in the bowtie, accounting for the 
entire left portion of the bowtie as a complete system. The improvements will reduce the frequency of fire by early elimination or identification of latent causal factors before ignition occurs, while addressing the interactions between all components throughout the system at the blunt and sharp ends of safety. While this paper focuses on a functional level looking at the increase of effectiveness as we move left on the bowtie, this presents a case for further in depth quantitative study with respect to barrier effectiveness from category 4-6, but highlights the requirement for a new method of analysis of Categories 1-3 (and possibly also integrating Category 4).

With a view to such future work, it is credible that a systemic approach, which can account for holistic goal-based fire safety and added focus on preventative measures could demonstrate an alternative design arrangement of equivalent safety. This would help push FSA, for example, further left in the preventative region and towards a systems-based analysis.

With respect to expanding on this future work, DBM provides scope for investigation. The ability to monitor processes has become far more accessible in providing a snapshot of a given condition. While such an approach currently focuses on the prevention of incidents close to the point of ignition, and where available technologies can provide feedback (Category 4), the integration of DBM to assist and strengthen barriers relating to Categories 2 and 3 , including procedural and organisational latent factors, is certainly of interest. It may also assist in the regulatory and research community's promotion of increased focus on prevention by addressing the interaction of various barriers across all categories of fire safety.

\section{Acknowledgements}

The authors wish to acknowledge and thank the contributions made to this research from the University of Strathclyde's Maritime Safety Research Centre and the technical contribution from our research sponsors DNVGL and Royal Caribbean Cruise Ltd.

\section{References}

1. Benito L, editor Taken from Big Data Technology for Maritime Safety. IMO International Conference; 2017; Busan, South Korea.

2. EMSA, Sweden STRIo, Veritas B, AB SR. Study investigating cost effective measures for reducing the risk from fires on ro-ro passenger ships (FIRESAFE), Appendix: Sensitivity and Uncertainty Analysis. 2016.

3. RCL RCCL. http://www.rclcorporate.com/rcl-innovators-are-big-names-at-newresearch-center/ 2017 [

4. EMSA. Published maritime casualty investigation reports 2018 [Available from: https://emcipportal.jrc.ec.europa.eu/index.php?id=44.

5. $\quad$ Engine Room Fires Can Be Avoided [press release]. Der Norske Veritas2000.

6. DNVGL. Recommended practice: Engine room fire prevention. 2018 January Report No.: DNVGL-RP-0279.

7. IMO. History of SOLAS fire protection requirements London: International Maritime Organisation, http://www.imo.org/en/OurWork/Safety/FireProtection/Pages/History-of-fireprotection-requirements.aspx; [Available from:

http://www.imo.org/en/OurWork/Safety/FireProtection/Pages/History-of-fire-protectionrequirements.aspx.

$8 . \quad$ Lundberg J, Rollenhagen C, Hollnagel E. What-You-Look-For-Is-What-You-Find The consequences of underlying accident models in eight accident investigation manuals.

Safety Science. 2009;47(10):1297-311.

9. Kristiansen S. Maritime transportation: safety management and risk analysis. 2005. 
10. Turner BA. Disasters, Man-Made. London: Wykeham Publications; 1978.

11. Dekker S, Pruchnicki S. Drifting into failure: theorising the dynamics of disaster incubation. Theoretical Issues in Ergonomics Science. 2014;15(6):534-44.

12. Rasmussen J. Risk management in a dynamic society: a modelling problem. Safety science. 1997;27(2):183-213.

13. Leveson N. Engineering a safer world: Systems thinking applied to safety: MIT press; 2011.

14. Rasmussen J. Risk management, adaptation, and design for safety. Future risks and risk management: Springer; 1994. p. 1-36.

15. Leveson NG. Applying systems thinking to analyze and learn from events. Safety science. 2011;49(1):55-64.

16. Dekker S. Drift into failure: From hunting broken components to understanding complex systems: CRC Press; 2016.

17. Read G, Salmon P, Lenné M. Sounding the warning bells: The need for a systems approach to understanding behaviour at rail level crossings. Applied Ergonomics 44:

Elsevier; 2013.

18. Besnard D, Hollnagel E. I want to believe: some myths about the management of industrial safety. Cognition, Technology \& Work. 2014;16(1):13-23.

19. Hollnagel E. Safety-I and safety-II: the past and future of safety management: CRC Press; 2018.

20. Meadows DH. Thinking in systems: A primer: chelsea green publishing; 2008.

21. Leveson, Dulac. Incorporating safety in early system architecture trade studies. Journal of Spacecraft and Rockets. 2009;46(2):430-7.

22. Qureshi ZH. A review of accident modelling approaches for complex socio-technical systems. Proceedings of the twelfth Australian workshop on Safety critical systems and software and safety-related programmable systems - Volume 86; Adelaide, Australia. 1387046: Australian Computer Society, Inc.; 2007. p. 47-59.

23. Dekker S. Drift into failure : from hunting broken components to understanding complex systems. Farnham, Surrey, England ;: Ashgate; 2011.

24. Rokseth B, Utne IB, Vinnem JE. A systems approach to risk analysis of maritime operations. Proceedings of the Institution of Mechanical Engineers, Part O: Journal of Risk and Reliability. 2017;231(1):53-68.

25. Wang YF, Xie M, Ng KM, Habibullah MS. Probability analysis of offshore fire by incorporating human and organizational factor. Ocean Engineering. 2011;38(17):2042-55.

26. Baalisampang T, Abbassi R, Garaniya V, Khan F, Dadashzadeh M. Review and analysis of fire and explosion accidents in maritime transportation. Ocean Engineering. 2018;158:350-66.

27. Wang YF, Qin T, Li B, Sun XF, Li YL. Fire probability prediction of offshore platform based on Dynamic Bayesian Network. Ocean Engineering. 2017;145:112-23.

28. Su S, Wang L. Three dimensional reconstruction of the fire in a ship engine room with multilayer structures. Ocean Engineering. 2013;70:201-7.

29. Jin Y, Jang B-S. Probabilistic fire risk analysis and structural safety assessment of FPSO topside module. Ocean Engineering. 2015;104:725-37.

30. Salem AM. Use of Monte Carlo Simulation to assess uncertainties in fire consequence calculation. Ocean Engineering. 2016;117:411-30.

31. Jin Y, Jang B-S, Kim J. Fire risk analysis procedure based on temperature approximation for determination of failed area of offshore structure: Living quarters on semidrilling rig. Ocean Engineering. 2016;126:29-46.

32. Kim SJ, Lee DH, Hong HM, Ahn SH, Park JB, Seo JK, et al. Methods for determining the optimal arrangement of water deluge systems on offshore installations. Ocean Engineering. 2016;114:236-49.

33. Kang HJ, Choi J, Lee D, Park BJ. A framework for using computational fire simulations in the early phases of ship design. Ocean Engineering. 2017;129:335-42.

34. Lee DH, Paik JK, Seo JK. Efficient water deluge nozzles arrangement on offshore installations for the suppression of pool fires. Ocean Engineering. 2018;167:293-309. 
35. Wang J, Jiao Y, Shi L, Xie Q, Li G, Liu J, et al. An experimental and non-dimensional study on the vertical temperature distribution of a sealed ship engine room fire. Ocean Engineering. 2018;165:22-33.

36. Wang J, Li G, Shi L, Xie Q, Zhang S. A mathematical model for heat detector activation time under ship fire in a long-narrow space. Ocean Engineering. 2018;159:305-14.

37. Yang R, Khan F, Yang M, Kong D, Xu C. A numerical fire simulation approach for effectiveness analysis of fire safety measures in floating liquefied natural gas facilities. Ocean Engineering. 2018;157:219-33.

38. Kim BJ, Kwan Seo J, Hyo Park J, Sung Jeong J, Keun Oh B, Hoon Kim S, et al. Load characteristics of steel and concrete tubular members under jet fire: An experimental and numerical study. Ocean Engineering. 2010;37(13):1159-68.

39. Kim JH, Kim DC, Kim CK, Islam MS, Park SI, Paik JK. A study on methods for fire load application with passive fire protection effects. Ocean Engineering. 2013;70:177-87.

40. Kim SJ, Lee J, Kim SH, Seo JK, Kim BJ, Ha YC, et al. Nonlinear structural response in jet fire in association with the interaction between fire loads and time-variant geometry and material properties. Ocean Engineering. 2017;144:118-34.

41. Wu B, Zong L, Yip TL, Wang Y. A probabilistic model for fatality estimation of ship fire accidents. Ocean Engineering. 2018;170:266-75.

42. IMO. MSC.1/Circ.1321, 2009 Guidelines for Measures to Prevent Fires in Engine Rooms and Cargo Pump Rooms. International Maritime Organisation; 2009.

43. Hollnagel E. Barriers and accident prevention: or how to improve safety by understanding the nature of accidents rather than finding their causes. Hampshire: Ashgate. 2016.

44. Hollnagel E. Barriers and accident prevention: or how to improve safety by understanding the nature of accidents rather than finding their causes. Hampshire: Ashgate. 2004.

45. Wróbel K, Montewka J, Kujala P. System-theoretic approach to safety of remotelycontrolled merchant vessel. Ocean Engineering. 2018;152:334-45.

46. Johnson WG. MORT safety assurance systems: Marcel Dekker Inc; 1980.

47. Leveson. Engineering a Safer World: Systems Thinking Applied to Safety: The MIT Press; 2012.

48. Hollnagel. Risk+barriers=safety? Safety Science. 2008;46(2):221-9.

49. Delvosalle C, Fiévez C, Pipart A, Fabrega JC, Planas E, Christou M, et al. Identification of reference accident scenarios in SEVESO establishments. Reliability Engineering \& System Safety. 2005;90(2-3):238-46.

50. Greenfield S. Dynammic barrier management. ESREL2016; 28/09/16; Glasgow2016.

51. Saleh JH, Marais KB, Bakolas E, Cowlagi RV. Highlights from the literature on accident causation and system safety: Review of major ideas, recent contributions, and challenges. Reliability Engineering \& System Safety. 2010;95(11):1105-16.

52. IMO. MSC/Circ.1002 Guidelines on Alternative Design and Arrangements for Fire Safety. International Maritime Organisation; 2001.

53. IMO. MSC.Circ.1212 Guidelines on Alternative Design and Arrangements for SOLAS Chapters II-I and III. International Maritime Organisation; 2006.

54. SFPE, NFPA. The SFPE Engineering Guide to Performance-Based Fire Protection Analysis and Design of Buildings. 2nd Edition ed: Society of Fire Protection Engineers and National Fire Protection Association; 2005.

55. International Convention for Safety of Life at Sea, SOLAS, Consolidated Edition. Sect. Chapter II, Regulation Four (2014).

56. IMO. ISM code : International safety management code and guidelines for its implementation. 4th edition, 2014 edition. ed2014.

57. ISO. FSS Code International Code for Fire Safety Systems. International Maritime Organisation; 2015.

58. ISO. ISO 14520:2015 Gaseous fire-extinguishing systems -- Physical properties and system design. 3rd Edition ed2015. 
59. IEC IEC. IEC 61511 Functional safety - Safety instrumented systems for the process industry sector. IEC, Geneva, Switzerland: IEC; 2017.

60. IMO. MSC.1/Circ.1533 Revised Guidelines on Evacuation Analysis for New and Existing Passenger Ships. International Maritime Organisation; 2016.

61. Lloyd's. Top 10 classification societies: Lloyd's List Maritime Intelligence; 2017 [Available from: https://lloydslist.maritimeintelligence.informa.com/LL1120174/Top-10classification-societies-2017.

62. ClassNK. 18-490 Rules for Integrated Fire Control Systems. 2018.

63. ClassNK. 18-460 Rules and Guidance for the Survey and Construction of Steel Ships, Part R Fire Protection, Detection and Extinction. 2018.

64. ABS. Guidance Notes on Fire-Fighting Systems. American Bureau of Shipping; 2015. 65. Lloyd's. Lloyd's Register Guidance Notes for Risk Based Analysis: Fire Loads and Protection. Lloyd's Register Group; 2014.

66. DNVGL. Rules for Classification of Ships, Part 4 Systems and Components, Chapter 11, Fire Safety. DNVGL Høvik2015.

67. DNV-GL. Rules for Classification: Ships DNVGL-RU-SHIP Pt.6 Ch.5. Edition July 2018, amended February 2019. 2019.

68. ISO. BS EN ISO 12100:2010 Safety of machinery - General Principles for design Risk assessment and risk reduction. BSI; 2010.

69. EU. Directive 2006/42/EC of the European Parliament

and of the Council of 17 May 2006 on Machinery, and Amending Directive 95/16/EC (recast). 2006.

70. IMO. MSC-MEPC.2/Circ.12/ Rev.1 Revised Guidelines for formal safety assessment (FSA) for use in the IMO rule making process. International Maritime Organisation; 2015.

71. IMO. MSC 83/INF.2 Formal Safety Assessment Consolidated text of MSC/Circ.1023MEPC/Circ.392. International Maritime Organisation; 2007.

72. Goerlandt F, Montewka J. Maritime transportation risk analysis: Review and analysis in light of some foundational issues. Reliability Engineering \& System Safety. 2015;138:11534.

73. Breinholt C, Ehrke K-C, Papanikolaou A, Sames PC, Skjong R, Strang T, et al. SAFEDOR-The Implementation of Risk-based Ship Design and Approval. Procedia - Social and Behavioral Sciences. 2012;48:753-64.

74. IMO. MSC 85/17/1 FSA - Cruise Ships, Formal Safety Assessment, Submitted by Denmark. International Maritime Organisation; 2008.

75. IMO. MSC 85/INF.2 FSA - Cruise Ships, Details of Formal Safety Assessment, Submitted by Denmark. International Maritime Organisation; 2008.

76. Wikman J, Evegren F, Rahm M, Leroux J, Breuillard A, Kjellberg M, et al. Study investigating cost effective measures for reducing the risk from fires on ro-ro passenger ships (FIRESAFE). European Maritime Safety Agency; 2017.

77. EMSA, Sweden STRlo, Offshore BVM, Rederi S. Second study investigating costefficient measures for reducing the risk from fires on ro-ro passenger ships (FIRESAFE II). 2018.

78. Schröder-Hinrichs JU, Baldauf M, Ghirxi KT. Accident investigation reporting deficiencies related to organizational factors in machinery space fires and explosions. Accident Analysis \& Prevention. 2011;43(3):1187-96.

79. Rollenhagen C, Westerlund J, Lundberg J, Hollnagel E. The context and habits of accident investigation practices: A study of 108 Swedish investigators. Safety Science. 2010;48(7):859-67.

80. Puisa R, Lin L, Bolbot V, Vassalos D. Unravelling causal factors of maritime incidents and accidents. Safety Science. 2018;110:124-41.

81. Puisa R, Williams S, Vassalos D. Towards an explanation of why onboard fires happen: The case of an engine room fire on the cruise ship "Le Boreal". Applied Ocean Research. 2019;88:223-32. 
82. Correia P. European Marine Casualty Information Platform a common EU taxonomy. 5th International Conference on Collision and Grounding of Ships (ICCGS); Espoo, Finland2010.

83. Beamer. Marine Safety Investigation Report, Fire in the engine compartment on board the Expedition-Cruiser Liner Le Boreal on 18th November 2015. 2016.

84. MSIU TM. Safety Investigation Report: MV Zenith, Fire in the Engine Room, 2013 Marine Safety Investigation Unit; 2014.

85. MAIB. Sea Gale Fire on 20 May 2014, Marine Accident Report. Danish Maritime Accident Investigation Board; 2015.

86. Lundberg J, Rollenhagen $\mathrm{C}$, Hollnagel $\mathrm{E}$. What you find is not always what you fixHow other aspects than causes of accidents decide recommendations for remedial actions. Accident Analysis \& Prevention. 2010;42(6):2132-9.

87. Carroll J. Incident reviews in high-hazard industries: sensemaking and learning under ambiguity and accountability. Industrial and Environmental Crisis Quarterly. 1995:175-97.

88. Carroll J. Organizational Learning Activities in High-Hazard Industries: The Logics Underlying Self-Analysis1998. 699-717 p.

89. Photonic ASA, editor Fiber Optic Linear Heat Monitoring. Passenger Ship Safety; 2017; Southampton.

90. Bistrović, Kezić, Komorčec. Historical Development of Fire Detection System Technology on Ships. https://hrcak.srce.hr/1126212013.

91. APM M. Oil Mist Detector Air Particle Monitor, Reference Manual, FGD-MAN-0077, Rev 7. 2017.

92. Tyco. IR6003/7 IR Oil Mist/ Smoke Detector, Technical Product Sales Data Sheet, Oil and Gas. 2015.

93. DASPOS, editor Oil Mist and Gas Leakage Detection - Early Warning System.

Passenger Ship Safety; 2017.

94. IMO. MSC/Circ. 1086 Code of Practice for Atmospheric Oil Mist Detectors.

International Maritime Organisation; 2003.

95. Photonics R. https://rebellionphotonics.com/products.html [

96. FLIR. http://www.flir.com/security/display/?id=83533 [

97. Heinrich $\mathrm{H}$, Peterson D, Roos N. Industrial Accident Prevention. 5th Edition ed: McGraw Hill, New York; 1980.

98. Reason J. Human Error: Cambridge University Press; 1990.

99. Everett C, Hall T, Insley S. NASA Accident Precursor Analysis Handbook, National Aeronautics and Space Administration Office of Safety and Mission Assurance2011.

100. Kim DH. Introduction to systems thinking: Pegasus Communications Waltham, MA; 1999.

101. DNVGL. Incident Investigation: Expert analysis is the key to preventing recurrences [Available from: www.dnvgl.com/services/incident-investigation-1095.

102. Sklet S. Methods for accident investigation. Norwegian University of Science and Technology; 2002.

103. Lundberg J, Rollenhagen C, Hollnagel E, Rankin A. Strategies for dealing with resistance to recommendations from accident investigations. Accident Analysis \& Prevention. 2012;45:455-67.

104. Rothblum AM. Human Error and Marine Safety. National Safety Council Congress and Expo,

Orlando, FL.2000.

105. Norman DA. Categorization of action slips. Psychological review. 1981;88(1):1.

106. Norman DA. The 'problem'with automation: inappropriate feedback and interaction, not 'over-automation'. Phil Trans R Soc Lond B. 1990;327(1241):585-93.

107. Puisa R, Williams S, Vassalos D. Systems Approach to Accident Analysis: Engine Room Fire on Cruise Ship "Le Boreal". International Maritime Conference on Design for Safety; 16-21 September Kobe, Japan2018. 
108. Rasmussen J. Information Processing and Human-Machine Interaction: An Approach to Cognitive Engineering, North-Holland Series in System Science and Engineering, 12: North-Holland New York; 1986.

109. Besnard D, Hollnagel E. I want to believe: some myths about the management of industrial safety Cogn Tech Work (2014) 16: 13. : Springer; 2014. 